\title{
Sensitivity of pigeons to prereinforcer and postreinforcer delay
}

\author{
A. W. LOGUE, MICHAEL E. SMITH, and HOWARD RACHLIN \\ State University of New York, Stony Brook, New York
}

\begin{abstract}
Delay between choice and receipt of reinforcement (prereinforcer delay) and delay between receipt of reinforcement and the next opportunity to choose (postreinforcer delay) were varied in a discretetrials choice paradigm using four pigeons. The pigeons consistently chose the reinforcer with the smaller prereinforcer delay. Variations in postreinforcer delay did not affect choice unless prereinforcer delays were equal. The results support previous findings that prereinforcer delays contribute disproportionately to the effects of rate of reinforcer access on choice in pigeons.
\end{abstract}

Pigeons will frequently choose a smaller over a larger reinforcer if the delay between choice and receipt of the smaller reinforcer is less than the delay between choice and receipt of the larger reinforcer. This behavior is defined as impulsiveness; choice of the larger, more-delayed reinforcer is defined as self-control. Pigeons exposed to this self-control paradigm often behave impulsively even when rates of access to the smaller and larger reinforcers are equal (Ainslie, 1974; Logue \& Pena-Correal, 1985; Logue, Rodriguez, Pena-Correal, \& Mauro, 1984; Mazur \& Logue, 1978; Rachlin \& Green, 1972).

Rate of reinforcer access is determined by prereinforcer delay (the delay between choice and receipt of a reinforcer) together with postreinforcer delay (the delay between a reinforcer and the next choice opportunity). Outside the laboratory, greater prereinforcer delay is often associated with smaller overall rate of reinforcer access. However, in the laboratory, prereinforcer delay and rate of reinforcer access can be varied independently by varying postreinforcer delay.

Rate of reinforcer access does affect pigeons' choices when prereinforcer delay is equal across alternatives (de Villiers, 1977). Thus, when prereinforcer delays are equal, pigeons are sensitive to postreinforcer delay (in this case, postreinforcer delay is equivalent to rate of reinforcer access). But when prereinforcer delays are not equal, as in the self-control paradigm, pigeons are insensitive to postreinforcer delay and rate of reinforcer access.

The data from several experiments support this conclusion. In one condition of Lea's (1979) experiment, pigeons chose between a reinforcer with a small prereinforcer de-

This research was supported by a University Award from the State University of New York to A. W. Logue, by NIMH Grant 1 RO3 MH 331101 to the State University of New York, A. W. Logue, principal investigator, and by grants from the National Science Foundation. We thank the many students who assisted in conducting the research, particularly A. Chavarro, T. Pena-Correal, and M. Rodriguez. Requests for reprints should be sent to A. W. Logue, Department of Psychology, State University of New York, Stony Brook, NY 11794. lay but a large postreinforcer delay, and a reinforcer of equal duration with a large prereinforcer delay but no postreinforcer delay. The pigeons chose the reinforcer with the small prereinforcer delay, even though rate of reinforcer access, and therefore total reinforcer access time, would have been greater had they chosen the reinforcer with the large prereinforcer delay. Logan (1965), using rats, has also found that prereinforcer delay is a stronger determinant of behavior than postreinforcer delay, although rats are sensitive to postreinforcer delays under some conditions (see Mellgren, Mays, \& Haddad, 1983).

Such data have resulted in quantitative models in which choice varies inversely with prereinforcer delay, independent of other aspects of reinforcement such as reinforcer size or rate of reinforcer access (see, e.g., Baum \& Rachlin, 1969; de Villiers, 1977; Fantino, 1977). Other models ignore prereinforcer delay and assume that animals behave so as to maximize reinforcement over long intervals (see Mazur, 1981, for a description of this type of model).

The overall purpose of the present experiment was to determine under what conditions naive pigeons were sensitive to postreinforcer delay in a laboratory self-control paradigm. Therefore, a discrete-trials procedure, similar to a self-control paradigm, was used. Postreinforcer delay was varied both while holding rate of reinforcer access constant and while allowing it to vary. Previous experiments, which showed no control by postreinforcer delays when prereinforcer delays were varied, used nondifferential postreinforcer stimuli for the two alternatives (see Logue et al., 1984; Mazur \& Logue, 1978). Consequently, stimuli associated with the most recent choice that had been made were present during the postreinforcer delay.

\section{METHOD}

\section{Subjects}

Four adult, experimentally naive White Carneaux pigeons, numbered $40,41,42$, and 43 , served as subjects. They were maintained at $80 \%$ of their free-feeding weights. 


\section{Apparatus}

The experimental chamber was $33 \mathrm{~cm}$ long, $29 \mathrm{~cm}$ wide, and $31 \mathrm{~cm}$ high. Two response keys mounted on one wall, $21 \mathrm{~cm}$ above the floor and $15 \mathrm{~cm}$ apart, required a minimum force of $.17 \mathrm{~N}$ to operate. The left key could be transilluminated with green light and the right key with red light. A food hopper below the keys, the bottom edge of which was $7 \mathrm{~cm}$ above the floor of the chamber, provided access to mixed grain when lit by two No. 1819 bulbs. The chamber could be illuminated by two 7.5 -W white lights, one $7.5-\mathrm{W}$ green light, or one $7.5-\mathrm{W}$ red light, through a Plexiglas-covered hole in the aluminum ceiling. The chamber was enclosed in a sound-attenuating box. This box contained an air blower for ventilation that also helped to mask extraneous sounds. A PDP-8/L computer in an adjacent room controlled the stimuli and recorded responses, using a SUPERSKED program.

\section{Procedure}

The pigeons were first trained to peck a key using an autoshaping procedure. The subsequent procedure was similar to that used by Logue and Mazur (1981), Logue and Pena-Correal (1984, 1985), Logue et al. (1984, Experiment 1), and Mazur and Logue (1978). Each session consisted of 34 trials -28 choice trials and 6 no-choice trials ( 3 no-choice trials for the left key and 3 no-choice trials for the right key).

At the beginning of each choice trial, the left key was transilluminated green and the right key was transilluminated red. The chamber was illuminated with white light. A single peck on either key produced a feedback click and turned both keys dark for a prereinforcer delay period, followed by a period of access to grain (reinforcement). After a green-key peck, the chamber was illuminated with green light during prereinforcer delay, reinforcer access, and postreinforcer delay periods. After a red-key peck, the chamber was illuminated with red light during prereinforcer delay, reinforcer access, and postreinforcer delay periods. Pecks on dark keys had no effect.

Postreinforcer delays lasted until a specified period of time (the programmed total trial time) had passed since the beginning of the previous trial (see Figure 1). If a period of reinforcer access did not end until after the programmed total trial time had passed, the next trial began immediately upon completion of that period of reinforcer access. This procedure kept overall rate of reinforcer access constant at the rate of 1 /programmed total trial time, provided that the sum of the latency to peck, the prereinforcer delay, and the period of reinforcer access on any given trial was no greater than the programmed total trial time.

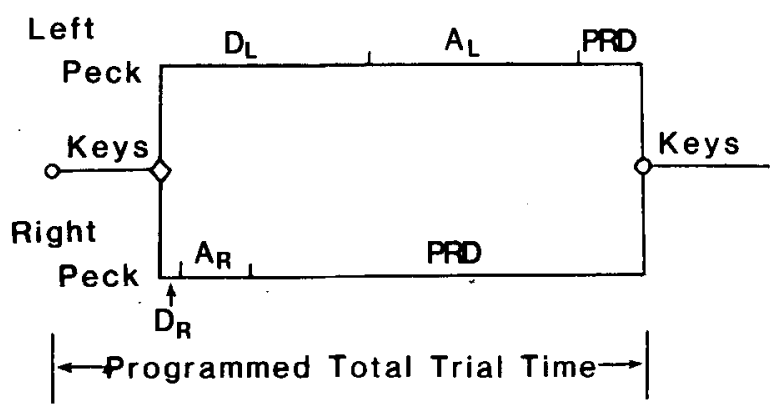

Figure 1. Diagram of the general procedure: At the beginning of a trial, the key lights were lit. If a left peck was made, it was followed by the appropriate prereinforcer delay $\left(D_{L}\right)$, reinforcer access $\left(A_{L}\right)$, and postreinforcer delay (PRD) periods, and then by a new trial. A similar sequence followed a peck on the right key. The programmed total trial time began timing each time the key lights came on. Postreinforcer delays lasted only until the programmed total trial time had timed out.
Table 1

The Conditions Used, the Order in Which They Were Conducted, and the Number of Sessions That Each Condition Was in Effect

\begin{tabular}{|c|c|c|c|c|c|c|}
\hline \multirow{2}{*}{$\begin{array}{c}\text { Condition } \\
\text { Number } \\
\end{array}$} & \multicolumn{4}{|c|}{$\begin{array}{c}\text { Reinforcer } \\
\text { Parameters (seconds)* }\end{array}$} & \multirow{2}{*}{$\begin{array}{l}\text { Programmed } \\
\text { Total Trial } \\
\text { Time (seconds) }\end{array}$} & \multirow{2}{*}{$\begin{array}{l}\text { Number of } \\
\text { Sessions }\end{array}$} \\
\hline & $A_{L}$ & $A_{R}$ & $D_{L}$ & $\mathrm{D}_{\mathrm{R}}$ & & \\
\hline I & 6 & 2 & 6 & .1 & 60 & 14 \\
\hline 2 & 6 & 2 & 6 & 1 & 50 & 11 \\
\hline 3 & 6 & 2 & 6 & .1 & 40 & 18 \\
\hline 4 & 6 & 2 & 6 & .1 & 30 & 11 \\
\hline 5 & 6 & 2 & 6 & .1 & 20 & 12 \\
\hline 6 & 6 & 2 & 6 & .1 & 17 & 25 \\
\hline 7 & 6 & 2 & 6 & .1 & 14 & 10 \\
\hline 8 & 6 & 2 & 6 & .1 & 12.5 & 13 \\
\hline 9 & 6 & 2 & 6 & 6 & 12.5 & 16 \\
\hline 10 & 6 & 6 & 6 & 6 & 12.5 & 48 \\
\hline 11 & 6 & 6 & 6 & 6 & left -30 , right -0 & 14 \\
\hline
\end{tabular}

${ }^{*} A_{\mathrm{L}}, A_{\mathrm{R}}, D_{\mathrm{L}}$, and $D_{\mathrm{R}}$ represent the amounts of the reinforcer access periods and the prereinforcer delays for the pecks on the left and right keys, respectively.

The no-choice trials required the pigeons to respond on only the left, green key or the right, red key. Only that key was lit, and pecking it led to the same sequence of events as on a choice trial. Pecks on the other key had no consequences. Left-key no-choice trials occurred on Trials 5,15 , and 25 ; right-key no-choice trials occurred on Trials 10,20 , and 30 .

Conditions were changed when the data satisfied a stability criterion. This criterion specified a minimum of 10 sessions per condition. In the last 5 consecutive sessions, the number of largereinforcer choices had to be neither higher nor lower than (i.e., within the range of) the number of large-reinforcer choices in all previous sessions within that condition. All of the pigeons had to simultaneously satisfy the stability criterion in order for a condition to be changed. Sessions were conducted 5 or 6 days per week.

Table I shows the conditions used, the order in which they occurred, and the number of sessions that each condition was in effect. For the first eight conditions the reinforcer-access periods (amounts) and the prereinforcer delays following pecks on the left and right keys, $A_{L}, A_{R}, D_{L}$, and $D_{R}$, were set at $6,2,6$, and $0.1 \mathrm{sec}$, respectively. Because $A_{L}$ plus $D_{L}$ was $12 \mathrm{sec}$, while $A_{R}$ plus $D_{R}$ was $2.1 \mathrm{sec}$, postreinforcer delays were $9.9 \mathrm{sec}$ shorter following pecks on the left key than following pecks on the right key (given equal latencies to peck both keys and long programmed total trial times). The programmed total trial time was decreased for each of the first eight conditions, beginning with $60 \mathrm{sec}$, then going to 50 , $40,30,20,17,14$, and $12.5 \mathrm{sec}$. This procedure kept overall rate of reinforcer access constant for pecks on either key while progressively decreasing postreinforcer delays.

The 9 th condition differed from the 8 th in that $D_{R}$ was changed to $6 \mathrm{sec}$. In the 10th condition, a further change was made by setting $A_{R}$ at $6 \mathrm{sec}$. In the 11 th condition, with $A_{L}, A_{R}, D_{L}$, and $D_{R}$ set at $6 \mathrm{sec}$, as they were in the 10th condition, the programming of the total trial time was changed. In this last condition, the programmed total trial time was set at $30 \mathrm{sec}$ following a peck on the left key, but at $0 \mathrm{sec}$ following a peck on the right key. Therefore, new trials always began immediately after the end of a reinforcer access period following a peck on the right key.

\section{RESULTS}

Data used for analyses were means from the last five sessions of each condition. Only data from the free-choice trials are reported below. Matched $t$ tests were used to compare data across conditions. Overall session time was 


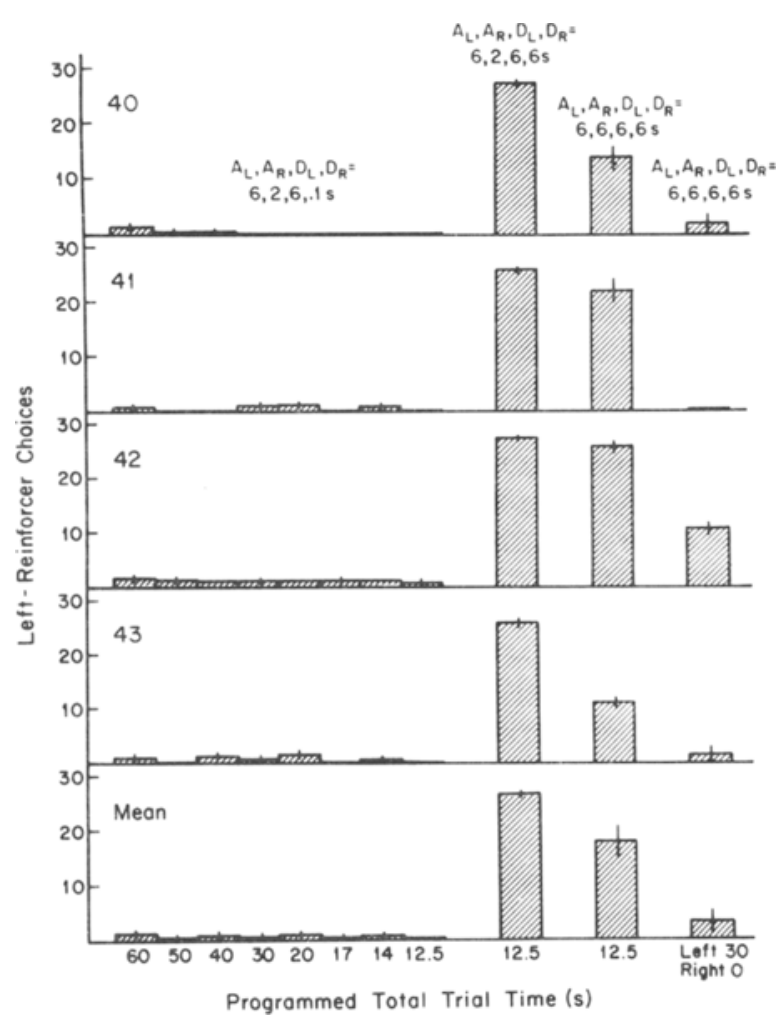

Figure 2. The number of left-reinforcer choices as a function of each condition. Separate values for each pigeon as well as the mean values over all four pigeons are shown. The vertical lines depict 1 $\mathrm{SE}$ on either side of the mean.

fairly constant across the 11 conditions for the four pigeons $(\mathrm{M}=19.5 \mathrm{~min}, \mathrm{SE}=4.3, \mathrm{~N}=4)$.

Figure 2 shows the number of left-reinforcer choices as a function of each condition. Separate values for each pigeon and the mean values over all four pigeons are shown. All of the pigeons made almost no left-reinforcer choices through the first 8 conditions. There were no significant changes in the number of left-reinforcer choices between any of these conditions, with the exception of that between the 1 st and the 2 nd conditions $[\mathrm{M}=1.0, \mathrm{SE}=0.3, \mathrm{~N}=4$, for the first condition, $\mathrm{M}=0.4$, $\mathrm{SE}=0.3, \mathrm{~N}=4$, for the 2 nd condition; $\mathrm{t}(3)=3.3, .02<$ $\mathrm{p}<.05]$. Because the pigeons almost always chose the small, right reinforcer during the first 8 conditions, they obtained a mean of only $34.6 \%$ of the maximum total reinforcer access time available ( $\mathrm{SE}=0.2, \mathrm{~N}=8$ conditions).

However, in the 9th condition, the number of leftreinforcer choices increased for each pigeon, almost to the maximum of $28(\mathrm{M}=0.2, \mathrm{SE}=0.1, \mathrm{~N}=4$, for the 8 th condition; $\mathrm{M}=26.8, \mathrm{SE}=0.4, \mathrm{~N}=4$, for the 9th condition, and this change was significant $[\mathrm{t}(3)=-72.8$, $\mathrm{p}<.002$ ]. In this condition, $97.0 \%$ of the maximum total reinforcer access time available was obtained $(\mathrm{SE}=0.9$, $\mathrm{N}=4$ pigeons).

The number of left-reinforcer choices decreased for each pigeon in the 10th condition $(M=18.2, S E=3.0$, $\mathrm{N}=4$ ), although this change missed significance $[\mathrm{t}(3)=$
$2.6, p \approx .08]$. The number of left-reinforcer choices again decreased for each pigeon in the 11 th condition $(M=3.6$, $\mathrm{SE}=2.1, \mathrm{~N}=4)$, and this change was significant $[\mathrm{t}(3)=$ $5.3, .01<p<.02]$. Any pattern of choices in these last two conditions yielded the maximum total reinforcer access time available because all reinforcer-access periods were set at 6 sec.

Table 2 shows the mean latencies to peck and the mean postreinforcer delays per trial, as well as the rate of periods of reinforcer access per minute of total session time. Data are shown separately for left and right periods of reinforcer access and for each pigeon. Means calculated over the data from the four pigeons are also shown. The latencies to peck tended to be higher on the side to which fewer pecks were made. This occurred in 25 out of 34 cases (four pigeons each studied in 11 conditions, minus 10 cases in which no left-reinforcer choices were made).

Because of these differences in the latencies to peck and in the programmed total trial time and the programmed values of $\left(A_{L}+D_{L}\right)$ and $\left(A_{R}+D_{R}\right)$, postreinforcer delays also varied. They decreased through the first 8 conditions until, in the 8th and 9th conditions, there was no postreinforcer delay for pecks on the left key. However, for pecks on the right key, there was an approximately 9-sec postreinforcer delay in the 8th condition and an approximately 3-sec postreinforcer delay in the 9th condition. In the 10th condition, all programmed values were equal for pecks to either key. In the 11th and last condition, there were no postreinforcer delays following pecks on the right key, but approximately $13 \mathrm{sec}$ of postreinforcer delay following pecks on the left key.

Reinforcer access rate was similar for pecks on either key from the 1st through the 7th conditions and in the 9 th and 10 th conditions. In the 8 th condition, virtually no left-reinforcer choices were made, so a comparison was not possible. In the 11th condition, rate of reinforcer access was higher following pecks on the right key.

\section{DISCUSSION}

In the first 8 conditions, all of the pigeons consistenly chose the reinforcer with the smaller prereinforcer delay. This occurred despite the fact that: (1) there were three forced choices for each of the two alternatives, (2) the reinforcer chosen was one-third as large as the other, (3) the overhead colored lights associated with the choice made were present during postreinforcer delays, (4) rate of reinforcer access was approximately equal no matter which reinforcer was chosen, (5) choice of the reinforcer with the smaller prereinforcer delay resulted in a larger postreinforcer delay, and (6) less total reinforcement was received because of these choices. This impulsiveness continued even in the 8th condition, in which there was a postreinforcer delay only following pecks on the side with the smaller prereinforcer delay.

In the 9th condition, the pigeons chose between small and large equally delayed reinforcers. All of the pigeons 
Table 2

The Mean Latencies to Peck per Trial (in Seconds), the Mean Postreinforcer Delays per Trial (in Seconds), and the Rate of Periods of Reinforcer Access per Minute of Total Session Time in Each Condition

\begin{tabular}{|c|c|c|c|c|c|c|c|c|c|c|c|c|}
\hline \multirow{3}{*}{$\begin{array}{l}\text { Condition } \\
\text { Number }\end{array}$} & \multicolumn{4}{|c|}{$\begin{array}{c}\text { Peck } \\
\text { Latencies }\end{array}$} & \multicolumn{4}{|c|}{$\begin{array}{l}\text { Postreinforcer } \\
\text { Delays }\end{array}$} & \multicolumn{4}{|c|}{$\begin{array}{c}\text { Reinforcer } \\
\text { Access Rate }\end{array}$} \\
\hline & \multicolumn{2}{|c|}{ Left } & \multicolumn{2}{|c|}{ Right } & \multicolumn{2}{|c|}{ Left } & \multicolumn{2}{|c|}{ Right } & \multicolumn{2}{|c|}{ Left } & \multicolumn{2}{|c|}{ Right } \\
\hline & Mean & $\mathrm{SE}$ & Mean & $\mathrm{SE}$ & Mean & $\mathrm{SE}$ & Mean & $\mathrm{SE}$ & Mean & $\mathrm{SE}$ & Mean & SE \\
\hline \multicolumn{13}{|c|}{ Pigeon 40} \\
\hline 1 & 1.5 & 0.2 & 1.1 & 0.0 & 46.5 & 0.2 & 56.8 & 0.0 & 1.0 & 0.0 & 1.0 & 0.0 \\
\hline 2 & 1.3 & 0.0 & 1.2 & 0.1 & 36.7 & 0.0 & 46.7 & 0.1 & 1.2 & 0.0 & 1.2 & 0.0 \\
\hline 3 & 2.0 & 0.7 & 1.7 & 0.6 & 26.0 & 0.7 & 36.3 & 0.5 & 1.5 & 0.0 & 1.5 & 0.0 \\
\hline 4 & . & . & 0.9 & 0.0 & . & & 27.0 & 0.0 & . & . & 2.0 & 0.0 \\
\hline 5 & & & 0.7 & 0.0 & & & 17.2 & 0.0 & & . & 3.0 & 0.0 \\
\hline 6 & 0.6 & 0.0 & 0.7 & 0.0 & 4.4 & 0.0 & 14.2 & 0.0 & 3.5 & 0.0 & 3.5 & 0.0 \\
\hline 7 & & . & 0.7 & 0.1 & . & & 11.2 & 0.1 & . & . & 4.3 & 0.0 \\
\hline 8 & & . & 0.9 & 0.1 & . & & 9.5 & 0.1 & & . & 4.8 & 0.0 \\
\hline 9 & 1.1 & 0.0 & 1.8 & 0.4 & 0.0 & 0.0 & 2.7 & 0.4 & 4.6 & 0.0 & 4.8 & 0.0 \\
\hline 10 & 1.6 & 0.1 & 1.5 & 0.1 & 0.0 & 0.0 & 0.0 & 0.0 & 4.4 & 0.0 & 4.4 & 0.0 \\
\hline 11 & 2.3 & 0.0 & 1.3 & 0.1 & 15.7 & 0.0 & 0.0 & 0.0 & 2.0 & 0.0 & 4.5 & 0.0 \\
\hline & & & & & Pigeon & 41 & & & & & & \\
\hline 1 & 0.8 & 0.0 & 2.0 & 0.1 & 47.2 & 0.0 & 55.9 & 0.1 & 1.0 & 0.0 & 1.0 & 0.0 \\
\hline 2 & . & . & 1.3 & 0.0 & . & . & 46.6 & 0.0 & · & . & 1.2 & 0.0 \\
\hline 3 & & . & 1.3 & 0.1 & & & 36.6 & 0.1 & 1.5 & 0.0 & 1.5 & 0.0 \\
\hline 4 & 1.1 & 0.2 & 1.2 & 0.0 & 16.9 & 0.2 & 26.7 & 0.0 & 2.0 & 0.0 & 2.0 & 0.0 \\
\hline 5 & 1.0 & 0.0 & 1.2 & 0.0 & 7.1 & 0.0 & 16.7 & 0.0 & 3.0 & 0.0 & 3.0 & 0.0 \\
\hline 6 & 2072.0 & 0.0 & 1.5 & 0.2 & 0.0 & 0.0 & 13.4 & 0.2 & 0.03 & 0.0 & 3.5 & 0.0 \\
\hline 7 & 0.7 & 0.0 & 1.4 & 0.1 & 1.3 & 0.0 & 10.6 & 0.0 & 4.3 & 0.0 & 4.3 & 0.0 \\
\hline 8 & & & 1.4 & 0.1 & & & 9.1 & 0.1 & . & . & 4.8 & 0.0 \\
\hline 9 & 1.7 & 0.0 & 1.8 & 0.2 & 0.0 & 0.0 & 2.8 & 0.2 & 4.4 & 0.0 & 4.8 & 0.0 \\
\hline 10 & 1.9 & 0.1 & 1.7 & 0.3 & 0.0 & 0.0 & 0.0 & 0.0 & 4.3 & 0.0 & 4.4 & 0.1 \\
\hline 11 & . & . & 1.8 & 0.0 & 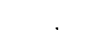 & . & 0.0 & 0.0 & . & . & 4.4 & 0.0 \\
\hline & & & & & Pigeon & 42 & & & & & & \\
\hline 1 & 88.9 & 50.1 & 52.6 & 27.1 & 27.6 & 7.6 & 54.0 & 0.7 & 0.7 & 0.1 & 0.7 & 0.1 \\
\hline 2 & 231.2 & 154.9 & 45.0 & 27.4 & 7.9 & 4.4 & 42.2 & 1.5 & 0.7 & 0.2 & 0.9 & 0.2 \\
\hline 3 & 149.7 & 88.0 & 29.3 & 24.2 & 14.2 & 5.3 & 34.2 & 1.4 & 1.0 & 0.3 & 1.3 & 0.2 \\
\hline 4 & 64.3 & 36.5 & 3.4 & 1.1 & 8.4 & 4.2 & 26.1 & 0.2 & 1.3 & 0.4 & 1.9 & 0.1 \\
\hline 5 & 2.5 & 0.5 & 1.5 & 0.1 & 5.6 & 0.5 & 16.5 & 0.1 & 3.0 & 0.0 & 3.0 & 0.0 \\
\hline 6 & 5.7 & 3.4 & 5.6 & 2.4 & 2.2 & 1.4 & 13.0 & 0.3 & 3.1 & 0.3 & 3.0 & 0.3 \\
\hline 7 & 8.2 & 2.7 & 1.9 & 0.8 & 0.0 & 0.0 & 10.8 & 0.1 & 3.2 & 0.4 & 4.1 & 0.2 \\
\hline 8 & 280.8 & 158.0 & 4.6 & 2.6 & 0.0 & 0.0 & 8.8 & 0.3 & 0.8 & 0.5 & 4.2 & 0.4 \\
\hline 9 & 2.4 & 0.1 & 2.3 & 0.8 & 0.0 & 0.0 & 2.2 & 0.8 & 4.2 & 0.0 & 4.8 & 0.0 \\
\hline 10 & 14.8 & 6.2 & 36.5 & 26.5 & 0.0 & 0.0 & 0.0 & 0.0 & 2.7 & 0.4 & 2.7 & 0.9 \\
\hline 11 & 69.4 & 55.2 & 5.2 & 1.0 & 13.4 & 0.4 & 0.0 & 0.0 & 1.5 & 0.3 & 3.6 & 0.2 \\
\hline & & & & & Pigeon & 43 & & & & & & \\
\hline 1 & 28.0 & 18.6 & 1.6 & 0.4 & 23.2 & 16.4 & 56.3 & 0.4 & 1.0 & 0.0 & 1.0 & 0.0 \\
\hline 2 & & & 1.6 & 0.4 & & & 46.3 & 0.4 & & & 1.2 & 0.0 \\
\hline 3 & 27.4 & 20.9 & 1.5 & 0.3 & 17.5 & 7.2 & 37.1 & 0.2 & 1.2 & 0.2 & 1.5 & 0.0 \\
\hline 4 & 1.3 & 0.5 & 1.0 & 0.1 & 16.8 & 0.5 & 26.9 & 0.1 & 2.0 & 0.0 & 2.0 & 0.0 \\
\hline 5 & 0.8 & 0.0 & 1.3 & 0.1 & 7.3 & 0.0 & 16.6 & 0.1 & 3.0 & 0.0 & 3.0 & 0.0 \\
\hline 6 & 3.3 & 0.0 & 1.1 & 0.0 & 1.7 & 0.0 & 13.8 & 0.0 & 3.5 & 0.0 & 3.5 & 0.0 \\
\hline 7 & 0.6 & 0.0 & 1.2 & 0.1 & 1.4 & 0.0 & 10.8 & 0.1 & 4.3 & 0.0 & 4.3 & 0.0 \\
\hline 8 & & & 0.9 & 0.0 & & . & 9.5 & 0.0 & & & 4.8 & 0.0 \\
\hline 9 & 1.2 & 0.0 & 1.7 & 0.2 & 0.0 & 0.0 & 2.8 & 0.2 & 4.6 & 0.0 & 4.8 & 0.0 \\
\hline 10 & 8.4 & 5.6 & 5.0 & 2.1 & 0.0 & 0.0 & 0.0 & 0.0 & 3.7 & 0.5 & 3.7 & 0.3 \\
\hline 11 & 39.5 & 0.0 & 3.6 & 1.6 & 10.7 & 0.0 & 0.0 & 0.0 & 1.0 & 0.0 & 4.0 & 0.3 \\
\hline & & & & & Mear & & & & & & & \\
\hline & 29.7 & 17.9 & 14.3 & 11.1 & 36.1 & 5.4 & 55.8 & 0.5 & 0.9 & 0.1 & 0.9 & 0.1 \\
\hline 2 & 116.2 & 81.3 & 12.3 & 9.4 & 22.3 & 10.2 & 45.5 & 1.0 & 1.0 & 0.2 & 1.1 & 0.1 \\
\hline 3 & 59.7 & 37.2 & 8.4 & 6.0 & 19.3 & 2.9 & 36.0 & 0.6 & 1.2 & 0.1 & 1.4 & 0.1 \\
\hline 4 & 22.2 & 17.2 & 1.6 & 0.5 & 14.0 & 2.3 & 26.7 & 0.2 & 1.8 & 0.2 & 2.0 & 0.02 \\
\hline 5 & 1.4 & 0.4 & 1.2 & 0.1 & 6.6 & 0.4 & 16.7 & 0.1 & 3.0 & 0.0 & 3.0 & 0.0 \\
\hline 6 & 520.4 & 447.9 & 2.2 & 1.0 & 2.1 & 0.8 & 13.6 & 0.2 & 2.5 & 0.7 & 3.4 & 0.1 \\
\hline 7 & 3.2 & 2.1 & 1.3 & 0.2 & 0.9 & 0.4 & 10.8 & 0.1 & 3.9 & 0.3 & 4.2 & 0.04 \\
\hline 8 & 280.8 & & 2.0 & 0.8 & 0.0 & . & 9.2 & 0.1 & 0.8 & . & 4.6 & 0.1 \\
\hline 9 & 1.6 & 0.3 & 1.9 & 0.1 & 0.0 & 0.0 & 2.6 & 0.1 & 4.4 & 0.1 & 5.1 & 0.4 \\
\hline 10 & 6.6 & 2.7 & 11.2 & 7.3 & 0.0 & 0.0 & 0.0 & 0.0 & 3.8 & 0.4 & 3.4 & 0.7 \\
\hline 11 & 37.1 & 15.9 & 3.0 & 0.8 & 13.3 & 1.2 & 0.0 & 0.0 & 1.5 & 0.2 & 3.7 & 0.3 \\
\hline
\end{tabular}


consistently chose the larger reinforcer, thus demonstrating that they were sensitive to changes in some of the contingencies present during the preceding 8 conditions, although not to changes in postreinforcer delays.

In the 10th condition, all of the pigeons' choices on the two keys moved towards equality, consistent with the fact that the consequences for pecks on either key were now equal. The 10th condition served as a baseline for the 11 th, in which the reinforcer amounts and prereinforcer delays were all set at $6 \mathrm{sec}$, but for which there was a postreinforcer delay only following pecks on the right key. In this last condition, all of the pigeons did finally show sensitivity to postreinforcer delay, making more choices of the reinforcer without any postreinforcer delay. Note, however, that this condition was the only one in which rate of reinforcer access, as well as postreinforcer delay, varied across the alternatives.

Together, the data from the 11 conditions suggest that pigeons' choices are sensitive to postreinforcer delays only to the extent that these delays affect rate of reinforcer access. Pigeons' choices are sensitive to prereinforcer delays whether or not rate of reinforcer access is affected. Integration of events over extended time periods can be observed with pigeons when immediate consequences for each of two choices are equal. In the last condition, the pigeons' choices were sensitive to postreinforcer delay, which covaried with reinforcer frequency, even though the prereinforcer delays were all set at $6 \mathrm{sec}$ and mean total trial time ranged between 13 and $95 \mathrm{sec}$.

These results are consistent with those of many previous experiments conducted with pigeons. For example, several researchers have shown strong control over pigeons' behavior by variations in prereinforcer delay but not by variations in more molar variables such as rate of reinforcer access (see Dunn \& Fantino, 1982; Lea, 1979; McDiarmid \& Rilling, 1965; Moore, 1979, 1982; Shull, Spear, \& Bryson, 1981). Hall-Johnson and Poling (1984) have recently shown that pigeons prefer a particular alternative with a shorter initial component, even if choice of that alternative yields less total food received over a session or if that alternative requires more responses to yield the same total access to food as another alternative. The present results add to all of these previous ones by directly comparing the effects of pre- versus postreinforcer delays and showing the stronger effect of the former within the context of a traditional self-control paradigm for pigeons. Prereinforcer delay is apparently a powerful determinant of pigeon choice behavior in the laboratory; postreinforcer delay and rate of reinforcer access varied along with prereinforcer delay appear to have relatively little effect.

In the present experiment, the pigeons were exposed to the first 8 conditions for a total of 192 sessions. Despite this extensive exposure to a choice between a larger reinforcer with a longer prereinforcer delay and a smaller reinforcer with a shorter prereinforcer delay, with forced choices of each alternative, virtually none of the larger reinforcers were chosen throughout these 8 conditions. Previous data have indicated that exposure to very gradual approximations of this choice, beginning with a choice between larger and smaller reinforcers with equal prereinforcer delays, is necessary for pigeons to acquire selfcontrol (Logue et al., 1984; Mazur \& Logue, 1978).

In conclusion, pigeons in discrete-trials self-control laboratory paradigms appear to be impulsive due to a lack of control over the pigeons' choices by postreinforcer delays. Pigeons are, however, sensitive to prereinforcer delay, independent of other aspects of reinforcement. Thus, pigeons' behavior in these paradigms is consistent with quantitative models of choice in which prereinforcer delay controls behavior (e.g., Baum \& Rachlin, 1969), but is inconsistent with models that ignore prereinforcer delay and assume that animals maximize reinforcement over long intervals (see Mazur, 1981). However, recall that, outside of the laboratory, prereinforcer delay often varies inversely with rate of reinforcer access. Thus, the pigeon's limited capacity to integrate events over time may not prevent it from maximizing reinforcement over long intervals in its natural habitat.

\section{REFERENCES}

AinsLie, G. W. (1974). Impulse control in pigeons. Journal of the Experimental Analysis of Behavior, 21, 485-489.

BaUm, W. M., \& RACHuin, H. C. (1969). Choice as time allocation. Journal of the Experimental Analysis of Behavior, 12, 861-874.

DE VILLIERS, P. (1977). Choice in concurrent schedules and a quantitative formulation of the law of effect. In W. K. Honig \& J. E. R. Staddon (Eds.), Handbook of operant behavior (pp. 233-287). Englewood Cliffs, NJ: Prentice-Hall.

DunN, R., \& Fantino, E. (1982). Choice and the relative immediacy of reinforcement. Journal of the Experimental Analysis of Behavior, 38, 321-326.

Fantino, E. (1977). Conditioned reinforcement: Choice and information. In W. K. Honig \& J. E. R. Staddon (Eds.), Handbook of operant behavior (pp. 313-339). Englewood Cliffs, NJ: Prentice-Hall.

Hall-Johnson, E., Poling, A. (1984). Preference in pigeons given a choice between sequences of fixed-ratio schedules: Effects of ratio values and duration of food delivery. Joumal of the Experimental Analysis of Behavior, 42, 127-135.

LEA, S. E. G. (1979). Foraging and reinforcement schedules in the pigeon: Optimal and non-optimal aspects of choice. Animal Behaviour, 27, 875-886.

LoGAN, F. A. (1965). Decision making by rats: Delay versus amount of reward. Journal of Comparative and Physiological Psychology, 59, $1-12$.

Logue, A. W., \& MAzUr, J. E. (1981). Maintenance of self-control acquired through a fading procedure: Follow-up on Mazur and Logue (1978). Behaviour Analysis Letters, 1, 131-137.

Logue, A. W., \& Pena-Correal, T. E. (1984). Responding during reinforcement delay in a self-control paradigm. Journal of the Experimental Analysis of Behavior, 41, 267-277.

Logue, A. W., \& Pena-Correal, T. E. (1985). The effect of food deprivation on self-control. Behavioural Processes, 10, 355-368.

Logue, A. W., Rodruguez, M. L., Pena-Correal, T. E., \& Mauro, B. C. (1984). Choice in a self-control paradigm: Quantification of experience-based differences. Journal of the Experimental Analysis of Behavior, 41, 53-67.

MAZUR, J. E. (1981). Optimization theory fails to predict performance of pigeons in a two-response situation. Science, 214, 823-824. 
Mazur, J. E., \& Logue, A. W. (1978). Choice in a "self-control" paradigm: Effects of a fading procedure. Journal of the Experimental Analysis of Behavior, 30, 11-17.

McDiarmid, C. G., \& Rilling, M. E. (1965). Reinforcement delay and reinforcement rate as determinants of schedule preference. Psychonomic Science, 2, 195-196.

Mellgren, R. L., Mays, M. Z., \& Haddad, N. F. (1983). Discrimination and generalization by rats of temporal stimuli lasting for minutes. Learning and Motivation, 14, 75-91.

MoORE, J. (1979). Choice and number of reinforcers. Journal of the Experimental Analysis of Behavior, 32, 51-63.
Moore, J. (1982), Choice and multiple reinforcers. Journal of the Experimental Analysis of Behavior, 37, 115-122.

Rachlin, H., \& Green, L. (1972). Commitment, choice and selfcontrol. Journal of the Experimental Analysis of Behavior, 17, $15-22$. Shull, R. L., SPEar, D. J., \& Bryson, A. E. (1981). Delay or rate of food delivery as a determiner of response rate. Journal of the $E x$ perimental Analysis of Behavior, 35, 129-143.

(Manuscript received September 5, 1984; revision accepted for publication January 23,1985 .) 